\title{
Kesenian Kuno Minahasa: Dari Perspektif Sejarah Publik
}

\author{
YUDA B. TANGKILISAN
}

K ajian Sejarah Indonesia memperlihatkan perkembangan yang menarik untuk disimak lebih lanjut. Arah dan jangkauan ditimbulkan oleh pengaruh aliran Posmodernisme, melainkan bergerak ke ranah publik. Perkembangan ini memunculkan suatu perhatian pada Sejarah Publik (Public History). Berbagai pemikiran, penelitian dan kegiatan dilakukan berkenan dengan pengembangan ranah pembahasan ini. Gerakan yang berasal dari publik (masyarakat) menarik perhatian kalangan akademik. Sejarah Publik menyadarkan mereka bahwa pengembangan sejarah tidak lagi monopoli dunia akademik. Justru, kalangan publik lebih giat dan agresif dalam merambah bidang-bidang pembicaraan sejarah. Berbagai karya diterbitkan yang secara kuantitas dan kualitas menyaingi produktivitas sejarawan akademik. ${ }^{1}$

Perkembangan ini dimungkinkan oleh maraknya media-media penerbitan atau pers. Pemikiran dan penulisan sejarah kalangan publik 
ini mendapat tempat dalam berbagai media. Apalagi di Indonesia perkembangan media televisi meramaikan lalu lintas informasi dalam masyarakat. Tidak jelas apakah karena tuntutan pengisin slot (matriks waktu) tayang atau memang terpanggil untuk mengembangkan budaya, media-media itu tidak jarang mengemas sejumlah tayangan yang berkaitan dengan sejarah. Selain media televisi, beberapa prakarsa muncul berkenan dengan upaya penyelematan, pelestarian dan pemanfaatan peninggalan sejarah dan budaya (historical and cultural heritage). Pembentukan komunitas pecinta warisan masa lampau bermunculan untuk memanfaatkan keberadaan situs dan museum sejarah. Mereka yang bergerak di sekitar penyampaian sejarah itu dapat disebut sebagai praktisi sejarah. Sebenarnya, jangkauan upaya mereka dalam memperkenalkan sejarah relatif lebih luas dan efektif, atau langsung kepada masyarakat, ketimbang insan akademik, yang kerap terlingkup dalam lingkungan seminar ilmiah dan sejenisnya.

Keterlibatan publik dalam kazanah budaya dan sejarah Minahasa telah lama tampak. Malahan, mereka merupakan perintis penulisan karya-karya sejarah berdasarkan sudut pandang dari dalam (view from within). Walau upaya itu tidak disokong oleh pijakan ilmiah berupa perangkat metodologi yang kritis. Berbekal kemampuan berbahasa sumber, terutama bahasa Belanda, mereka menyajikan tulisan tentang masa lampau negeri mereka.

Ketika perkembangan dunia akademik, termasuk Ilmu Sejarah, menyentuh cakrawala kehidupan intelektual Minahasa, sejumlah pakar sejarah yang berlatarbelakangkan pendidikan Ilmu Sejarah muncul dan menghasilkan sejumlah karya. Berbagai seminar dan pertemuan ilmiah lainnya digelar yang melibatkan mereka. Suatu gejala yang menarik adalah bahwa kegiatan-kegiatan itu tidak meninggalkan para peminat sejarah yang tidak pernah menempuh pendidikan formal di bidang kajian Sejarah. Perkembangan selanjutnya memperlihatkan bahwa kazanah penulisan sejarah Minahasa disemarakan oleh sejarawan mancanegara atau para Minahassanists (Indonesianists).

Memang, perhatian kalangan bukan sejarawan akademis terhadap historiografi Minahasa tetap berlangsung. Malahan mereka tampak lebih produktif dalam menghasilkan karya-karya. Selain itu, mereka kerap mengambil prakarsa untuk menggali dan menyingkap masa lalu Minahasa. Wujud perhatian mereka tidak hanya terbatas pada penulisan karya tertulis tetapi juga kegiatan lainnya yang berkaitan dengan kesejarahan dan bersentuhan langsung dengan masyarakat, seperti pameran, pendirian museum, pagelaran dan sejenisnya. 


\section{Sejarah Publik}

Gejala keterlibatan publik dalam masalah kesejarahan, sebagaimana telah dipaparkan, menelurkan gagasan tentang pengembangan ranah Sejarah Publik. Berbagai batasan diajukan berbagai kalangan yang memperlihatkan dinamika pengembangan Sejarah Publik. ${ }^{2}$ Berbagai lembaga penelitian Sejarah Publik muncul terutama di mancanegara, seperti Amerika Serikat dan Australia. Dari berbagai pemikiran itu tampak bahwa Sejarah Publik berada di antara rentangan antara perkembangan mutakhir dari kajian Sejarah Sosial dan revitalisasi Sejarah Populer. ${ }^{3}$ Sejarah Publik menjembatani lingkungan akademik dan masyarakat peminat serta pecinta sejarah.

Selanjutnya, dalam mengamati dan mencermati perkembangan tersebut, pembahasan ini menempatkannya dalam suatu konteks diakronis yang berjangka panjang. Manfaat perspektif diakronis adalah memperlihatkan arah, perubahan dan dinamika. Sumber yang digunakan dalam perspektif ini adalah karya-karya yang telah dihasilkan, mulai dari bentuk tertulis hingga kegiatan-kegiatan. Kerangka analisis berikutnya adalah apa yang disebut dengan Publik Sejarah (Historical Public). Sebelumnya, kalangan sejarawan telah mengenal apa yang dikatakan sebagai masyarakat sejarah (historical society). Istilah ini mengacu pada organisasi profesi sejarah, seperti di Indonesia adalah Masyarakat Sejarawan Indonesia (MSI), yang sebenarnya tidak hanya berisikan sejarawan akademik tetapi juga sejarawan non akademik. Kerangka analisis ini menempatkan cakupan Publik Sejarah pada konteks yang lebih luas, yaitu kesemua profesi dan lembaga yang memberikan perhatian dan bergiat dalam pengembangan sejarah, baik melalui sumber-sumber sejarah maupun peninggalanpeninggalan sejarah. Sebagaimana diketahui bahwa masa lampau meninggalkan jejak-jejaknya tidak hanya secara tertulis tetapi juga tidak tertulis, seperti benda dan tradisi lisan. ${ }^{4}$ Publik Sejarah mencakup kalangan akademisi dan non akademisi sejarah. ${ }^{5}$

Peninggalan masa lampau relatif tidak utuh. Berbagai faktor mempengaruhi ketersediaan dan keberlangsungan benda-benda itu. Tentang warisan budaya (cultural heritage) Minahasa, terutama budaya kebendaan (material/ tangible culture), Hetty Palm (1958) pernah menyatakan bahwa sejumlah kesenian Minahasa lama (ancient arts) telah menghilang. Faktor penyebab utamanya adalah pengenalan dan perkembangan agama Kristen yang tidak memberikan ruang untuk keberadaan tradisi dan benda kesenian itu terutama yang bertalian dengan ritual keagamaan karena dipandang bid'ah. 
Penggalian kembali budaya masa lampau Minahasa banyak dilakukan oleh kalangan publik. Melalui berbagai bentuk kegiatan mereka mereka ulang warisan sejarah itu. Sebagian upaya itu berlandaskan pada topangan sumber-sumber dari masa lampau, sebagian lainnya tidak melakukan hal tersebut. Oleh karena itu, beberapa hasil yang disampaikan tidak dapat dipertanggungjawabkan, terutama dari kacamata ilmiah. Namun, dibandingkan dengan kalangan akademik, mereka lebih memperlihatkan tingkat produktivitas yang lebih tinggi dalam wujud karya nyata di ruang publik. Oleh karena itu, Sejarah Publik antara lain merupakan jembatan untuk mempertemukan kalangan publik sejarah ini agar berdialog, berinteraksi hingga bersinergi dalam menggali, memelihara, mengembangkan dan memanfaatkan kekayaan warisan budaya dan masa lampau Minahasa, sehingga memberikan manfaat yang optimal terhadap kemajuan kehidupan masyarakat dan pengembangan ilmu pengetahuan. Kekayaan Minahasa perlu dibawa ke tingkat yang lebih tinggi daripada sekedar konteks daerah, menuju taraf nasional, regional dan internasional. ${ }^{6}$

\section{Perkembangan Kajian Minahasa}

Pada tahun 1981 terbit sebuah karya bibliografi beranotasi tentang Minahasa dan Bolaang Mongondow yang melengkapi dan merangkum karya-karya sejenis yang dibuat sebelumnya. Karya ini membatasai cakupan pembahasannya pada antara tahun 1800 hingga $1924 .{ }^{7}$ Mieke Schouten (1981: 1-2), yang menyusun karya itu, mengkategorikan penulis-penulis tentang Minahasa ke dalam beberapa kriteria, yakni penyebar agama (misionaris dan zending), pejabat pemerintahan kolonial (dan pensiunannya), ahli hukum adat, naturalis, ahli bahasa, ilmuwan sosial, dan jurnalis. Memang, dalam karya ini sulit untuk menelusuri penulisan awal tentang Minahasa, namun tampak sejumlah penulis-penulis Minahasa telah berkarya pada abad ke-19. Beberapa nama yang dapat disebut adalah seperti L. Mangindaan (1860; 1873), A.B. Kalengkongan (1896), A.L. Waworuntu (1893; 1894) dan lainnya. ${ }^{8}$ Menelaah perkembangan penulisan sejarah di Minahasa masa pasca kolonial, tampaknya kerangka yang diajukan oleh Taufik Abdullah dan Abdurrachman Surjomihardjo (1985: 27-29) berupa sejarah ideologi, pewarisan nilai dan akademik memperlihatkan kesesuaian dalam tingkat tertentu. Namun, untuk memudahkan pengamatan, kategori yang lebih sederhana dan mudah difahami adalah sejarawan akademik dan nonakademik. Sejarawan nonakademik Minahasa meliputi A. Pantouw (1926), J.A Worotikan (1933) H.M. Taulu (1934; 1937), F.S. 
Watuseke (1968), R.H. Kotambunan (1985), Bert Supit (1986; 1993), Jessy Wenas (2007), H.B. Palar (trilogi 2009) dan lainnya.

Kalangan sejarawan akademik mencakup F.W. Parengkuan, A.B. Lapian, R.Z. Leirissa, Bertha Pantouw dan yang berasal dari generasi mudanya F.R. Mawikere. Juga pakar yang tidak dapat dilupakan adalah Alex J. Ulaen. Beberapa pakar lain yang berasal dari disiplin Ilmu Sejarah ikut menyemarakkan perbincangan ilmiah tentang masa lalu Minahasa, seperti Nico S. Kalangie, E.K.M. Masinambouw, dan G.Y.S Manoppo- Watupongoh. Mereka mengimbangi pandangan tentang perkembangan sejarah dan masyarakat Minahasa dari kalangan sejarawan mancanegara (Minahasanis atau Indonesianis), seperti Tim Babcock (1989), Barbara Sillars-Harvey (1984), Muriel Charas (1987), Mieke Schouten (1993), David Henley (1995) dan lainnya. David Henley barangkali perlu diberi penghargaan khusus atas ketekunan dan kekonsistenannya dalam mengembangan kajian masa lampau Minahasa melalui berbagai karya yang dihasilkannya, baik secara mandiri atau bersama (kelompok).

Perkembangan penulisan sejarah akademik itu memperlihatkan pergeseran perhatian dan tema. Sejarah Minahasa tidak lagi dibahas dari sudut politik tetapi telah merambah ke bidang lainnya seperti sosial, ekonomi dan budaya. Perangkat metodologinya juga memperlihatkan perkembangan dari pendekatan individualis, struktural hingga strukturistik. Namun tampaknya seiring dengan kepergian sejumlah sejarawan akademik, suatu ruang kosong terjadi dalam penelitian dan penulisan masa lampau Minahasa.

\section{Publik Sejarah Minahasa}

Sebagaimana telah diungkapkan di atas, perhatian terhadap masa lampau dan budaya Minahasa tidak hanya berlangsung di lingkungan akademik. Justru perkembangan perhatian di luar lingkungan ilmiah itu lebih semarak dan penuh karya. Oleh karena itu, ruang kosong yang saat in terasa tampaknya secara tidak langsung terisi oleh kesemarakan dan dinamika tersebut. Melalui berbagai kegiatan ilmiah dan budaya, yang diprakarasai mereka, sebagai bagian dari public sejarah Minahasa, membuka kesempatan untuk sejarawan-sejarawan muda tampil dan mengasah diri untuk segera melanjutkan pengembangan penelitian dan penulisan sejarah Minahasa.

Merunut kembali ke perspektif sejarah tentang kiprah publik sejarah itu, perhatian akan menuju pada keberadaan sejumlah organisasi kekerabatan dan sosial budaya hingga lembaga penelitian. Kerukunan Keluarga Kawanua merupakan perkumpulan kekerabatan yang 
dibentuk untuk wadah bertemu para Minahasa di perantauan (diaspora), terutama di Jakarta. ${ }^{9}$ Organisasi yang berkiprah langsung dalam pengembangan sejarah dan budaya Minahasa antara lain adalah Yayasan Kebudayaan Minahasa (YKM), Kerukunan Antar Pemuda Kawanua (KAPAK), Yayasan Penelitian Sejarah dan Masyarakat, Yayasan Malesung Rondor dan Institut Seni Budaya Sulawesi Utara. Sebagian besar lembaga tersebut sudah memudar dan bahkan menghilang dari kegiatan pengembangan sejarah dan budaya Minahasa, kecuali yang disebutkan terakhir. Beberapa perintis dan pemrakarsa pengembangan itu antara lain adalah mulai dari Non Tengker, Benny J. Tengker, Bert Supit, H.N. Sumual hingga Benny J. Mamoto. Seorang budayawan Minahasa yang sangat ulet, teguh dan bededikasi tinggi adalah Jessy Wenas. Melalui Institut Seni Budaya Sulawesi Utara, Benny J. Mamoto memperlihatkan perhatian dan kerja keras tanpa pamrih dalam mengembangkan warisan sejarah dan budaya leluhurnya sebagai bagian dari kebudayaan dan sejarah nasional. ${ }^{10}$

Sambutannya pada karya Benny Mamoto (2007: th) menyatakan bahwa 'suatu gerakan kebudayaan - yang antaranya ditandai serangkaian program penelitian, seminar dan symposium, konservasi dan dokumentasi, pelatihan/workshop, apresiasi seni dan festival/lomba yang meliputi setiap cabang seni tradisional Sulawesi Utara (baca juga Minahasa, pen) - kami tujukan tak lain untuk melestarikan dan mengembangkan seni budaya warisan leluhur yang di atas mana dapat dibangin secara lebih kokoh kebudayaan generasi hari ini dan generasi-generasi mendatang.' Semangat dan tujuannya di balik prakarsa dan pelaksanaan gerakan kebudayaan itu tampak pada pernyataan selanjutnya yang berbunyi adalah 'bila di masa lampau orang Minahasa telah terbukti unggul di hampir setiap bidang kehidupan dibandingkan dengan umumnya etnis lain di seluruh Nusantara, nilai-nilai budaya apa saja yang melatarbelakanginya? Sejumlah nilai budaya tradisional Minahasa sangatlah relevan dan penting untuk dihayati serta dilestarikan generasi kini dan nanti. Sebut sebagai missal, nilai-nilai budaya tumani o rumapar (keluar dari kampung halaman untuk membuka lahan penghidupan baru dan mencapai keberhasilan puncak) yang di masa sekarang ini kurang-lebih selaras dengan semangat outward looking yang merupakan syarat mentalitas untuk bisa unggul di era globalisasi'.

\section{Menjembatani antar Komponen Publik Sejarah}

Kegalauan dan rintisan Hetty Palm hampir enam dekade yang lalu tampaknya telah ditanggapi oleh karya Jessy Wenas (2007). Walau tanpa 
berlatarbelakangkan pendidikan akademik, baik dari bidang Ilmu Sejarah dan bahasa Belanda, budayawan ini mencoba merambah literatur-literatur lama yang sebagian besar berbahasa Belanda untuk menggali dan merekonstruksi kembali peninggalan kesenian Minahasa dan upayanya dapat dikatakan berhasil.

Tentunya, sebagaimana yang disadari bahwa masa lampau hanya meninggalkan sedikit jejak-jejaknya di masa kini dan adagium luhur (the noble dream) namun utopis dari Bapak Sejarah Modern Leopold von Ranke tentang merekonstruksi kembali masa lalu sebagaimana yang terjadi (wie ist eigenlicht gewessen), upaya penggalian itu masih menyisakan rongga-rongga yang tidak dapat disi kembali karena telah menghilang tertelan oleh waktu. Oleh karena itu selain menemukan kembali (rediscovery) upaya itu memerlukan suatu penciptaan (kreasi) berdasarkan imajinasi yang dapat dipertanggungjawabkan dan sekaligus menjawab tantangan (jiwa) zaman saat ini (zeitgeist).

Upaya menggali, melestarikan dan memperkenalkan warisan kesenian Minahasa dalam berbagai forum yang dewasa ini banyak diprakarsai oleh Benny J. Mamoto memperlihatkan kedua sisi itu, yaitu rediscovery dan creation (invention). Memang, temuan-temuan ini relatif belum menjadi perhatian kalangan (sejarawan) akademisi terutama sebagai bahan dan masukan untuk penelitian dan penulisan ilmiah. Walau demikian, kesenjangan itu tidak lebih sebagai persoalan waktu belaka, karena cepat atau lambat jembatan itu, berupa Sejarah Publik, telah terbangun dan menanti untuk digunakan. Permasalahan yang penting di balik perkembangan Sejarah Publik di kalangan publik sejarah adalah adanya kesadaran bahwa rediscovery dan invention itu tidaklah bertolakbelakang selama didukung oleh landasan ilmiah, dan selanjutnya upaya itu dimaksudkan sebagai bagian dari pengembangan kekayaan kazanah kebudayaan nasional yang demikian majemuk dan dinamis.

\section{Endnotes}

\footnotetext{
${ }^{1}$ Roy Rosenzweig and David Thelen, The Presence of the Past: Popular Uses of History in American Life, Columbia University Press, New York, 1998 and Paul Ashton and Hilda Kean (eds), Public History and Heritage Today: People and Their Pasts, Palgrave Macmillan, Basingstoke, 2012.

${ }^{2}$ Lihat antara lain dalam Benson, Brier, Rosenweig (1986); juga dalam situs internet seperti: http://www.nyu.edu/gsas/dept/history/publichistory/main.htm, www.publichistory.org/what is/definition.html http://ncph.org/cms/what-is-publichistory/dan lainnya

${ }^{3}$ Seperti pembatasan sebagai berikut, 'Public history is history that is seen, heard, read, and interpreted by a popular audience. Public historians expand on the methods of academic history by emphasizing non-traditional evidence and presentation formats, reframing questions, and in the process creating a distinctive historical practice... Public history is also history that belongs to the public. By emphasizing the public context of scholarship, public
} 


\footnotetext{
history trains historians to transform their research to reach audiences outside the academy.' (http://www.nyu.edu/gsas/dept/history/publichistory/main.htm)

${ }^{4}$ Tradisi Lisan berbeda dengan Sejarah Lisan yang lebih diartrikan sebagai metode untuk menggali keterangan dari para saksi sejarah melalui pada umumnya teknik wawancara. Lihat masalah-masalah dalam Sejarah Lisan pada Notosusanto (1978: 17-21).

${ }^{5}$ Bandingkan dengan profesi sejarah yang diungkapkan oleh Kuntowijoyo (1995: 3-6), yaitu guru sejarah, pegawai sejarah (purbakala, museum, monumen, balai kajian sejarah dan arsip), pencatat sejarah (di instansi-instansi seperti ABRI (Angkatan Bersenjata Republik Indonesia), kini TNI (Tentara Nasional Indonesia) dan POLRI (Kepolisian Republik Indonesia), pelaku sejarah, saksi sejarah, peneliti sejarah, dan penulis sejarah. Suatu hal yang menarik di sekitar pegawai sejarah adalah tentang tugas mereka yang berhubungan dengan masyarakat untuk menanamkan kesadaran sejarah, yang dikatakannya tidak mudah karena harus bersaing dengan pengaruh globalisasi yang tidak jarang memberikan sajian yang tidak hanya anasional tetapi juga ahistoris.

${ }^{6}$ Tidaklah berlebihan apabila harapan diberikan juga kepada masyarakat Minahasa agar mampu memberikan sumbangsih yang sesuai untuk kemajuan kehidupan bangsa dan negara Indonesia. Pada konteks ini, gagasan-gagasan yang disampaikan oleh berbagai pakar tentang bagaimana membangun dan memajukan Indonesia perlu menjadi acuan, antara lain adalah Sastrosoenarto (2006: 101-104). Melengkapi pemikiran bernas itu adalah karya Sukmawati \& Tangkilisan (2012). Lihat juga sambutan Benny J. Mamoto pada karya Wenas (2007: th).

${ }^{7}$ Pembatasan periodisasi ini tidaklah ketat karena tercantum karya M.R. Dajoh (1949) dan F.S. Watuseke (1972) pada halaman 53.

${ }^{8}$ Judul karya mereka yang lengkap terdapat pada Schouten (1981)

${ }^{9}$ Lihat pembahasan yang menarik tentang Diaspora Minahasa pada A.J. Ulaen (2002).

${ }^{10}$ Simak pencapaian dan penghargaan yang diperoleh oleh Benny J. Mamoto dalam revitalisasi kesenian Minahasa pada: http://www.guinnessworldrecords.com/records-7000/largestorchestra-playing-on-bamboo-instruments/; http://umum.kompasiana.com/2009/11/01/seni-budaya-indonesia-dan-pengakuandunia/; http://oase.kompas.com/read/2009/11/05/07410886/Bakudapa.di.Pasang.Surut.Kolintang; http:// www.fib.ui.ac.id/index.php?limitstart=78\&lang.
}

\section{Daftar Pustaka}

Abdullah, Taufik, Abdurrachman Surjomihardjo (red.) (1985). Ilmu Sejarah dan Historiografi Arah dan Perspektif. Jakarta: Gramedia.

Charas, Muriel (1987). 'Une vue generale sur le pays Minahasa'. Archipel, 34, hal. 49-62

Charas, Muriel (1987). 'Le giroflier: evolution de l'agriculture et transformation de l'espace on pays Minahasa'. Archipel, 34, hal. 143-163

Henley, David E.F (1996). Nationalism and Regionalism in a Colonial Contex, Minahasa in the Dutch East Indies, Leiden: KITLV Press.

Kotambunan, R.E.H. (1985). Minahasa II \& III Pemerintahan Purba sampai Kedatangan VOC dan Tiga Perang Tondano. Manado: tp.

Kuntowijoyo (1995). Pengantar Ilmu Sejarah. Yogyakarta: Yayasan Bentang Budaya.

Lapian, A.B. (2009). Orang Laut Bajak Laut Raja Laut Sejarah Kawasan Laut Sulawesi Abad ke-19. Jakarta: Komunitas Bumbu.

Leirissa, R.Z. (1991). PRRI Permesta Strategi Membangun Indonesia tanpa Komunis. Jakarta: Pustaka Utama Grafiti.

Leirissa, R.Z. (1997). Minahasa di Awal Perang Kemerdekaan Indonesia Peristiwa Merah Putih dan SebabMusababnya. Jakarta: Pustaka Sinar Harapan \& Yayasan Malesung Rondor.

Notosusanto, Nugroho (1978). Masalah Penelitian Sejarah Kontemporer (suatu pengalaman). Jakarta: Yayasan Idayu.

Pantouw, A (1926). Minahasa Lama dan Baru. Manado: Manadosche Drukkerij.

Palar, H.B. (2009). Wajah Lama Minahasa. Jakarta: Yayasan Gibbon Indonesia.

Palar, H.B. (2009). Wajah Baru Minahasa. Jakarta: Yayasan Gibbon Indonesia.

Palar, H.B. (2009). Minahasa Benteng Terakhir NKRI. Jakarta: Yayasan Gibbon Indonesia.

Parengkuan, F.E.W (1983). Sejarah Sosial Sulawesi Utara. Jakarta: Proyek ISDN.

Sastrosoenarto, Hartarto (2006). Industrialisasi serta Pembangunan Sektor Pertanian dan Jasa Menuju Visi Indonesia 2030. Jakarta: Gramedia Pustaka Utama. 
Schouten, Mieke (1981). Minahasa and Bolaangmongondow an Annotated Bibliography 1800-1942. The Hague: Martinus Nijhoff.

Schouten, Mieke (1993). Minahasan Metamorphoses Leadership and Social Mobility in a Southeast Asian Society. Leiden: Disertasi S-3 Universitas Leiden.

Schefold, Reimar (ed.) (1995). Minahasa Past and Present: Tradition in an Outer Island Region of Indonesia. Leiden: Research School CNWS.

Sukmawati, Carmelia, Yuda B. Tangkilisan (2012). Perjalanan Pemikiran dan Karya Hartarto Sastrosoenarto Menteri Perindustrian 1983-1993 Menteri Koordinator 1993-1999. Jakarta: Yayasan Pidi.

Supit, Bert (1986). Minahasa dari Amanat Watupinawetengan hingga Gelora Minawanua. Jakarta: Penerbit Sinar Harapan.

Supit, Bert (tt). Sejarah Perang Tondano (Perang Minahasa di Tondano). Jakarta: Yayasan Lembaga Penelitian Sejarah dan Masyarakat.

Tangkilisan, Yuda B, M.P.B. Manus (2002). 'Tinjauan Ringkas tentang Historiografi Minahasa' dalam: Roy E. Mamengko (ed.). Etnik Minahasa dalam Akselerasi Perubahan. Jakarta: Pustaka Sinar Harapan, hal 372-380.

Taulu, H.M. (1934). Hikajat Hermanus Willem Dotulong, Opperhoofdof Majoor van Sonder, (1824-1861) en Groot-Majoor titulair bij de infantrie v.h. Nederlandsch oost-Indische-leger, (1825-1830). Manado: Liem .

Taulu, H.M. (1937). Sedjarah 'perang tondano' (1807-1809) Ringkasan. Manado: Liem.

Ulaen, Alex J. (2002). 'Kembara Budaya dan Diaspora: Amatan (dari) Luar'. Dalam: Roy E. Mamengko (ed.). Etnik Minahasa dalam Akselerasi Perubahan. Jakarta: Pustaka Sinar Harapan, hal 400-8.

Watuseke, F.S. (1968). Sedjarah Minahasa. Mando: tp.

Wenas, Jessy (2007). Sejarah \& Kebudayaan Minahasa. Jakarta: Institut Seni Budaya Sulawesi Utara.

Worotikan, J.A. (1933/37). Geschiedenis uit de Sagen van de Minahasa, 2 jli. Manado: Lie Boen Yat. 